\title{
Distributions of Bus Stop Spacings in the United States
}

\author{
Ayush Pandey $^{1}$ (), Lewis Lehe ${ }^{1}$ (), Dana Monzer ${ }^{1}$ (1) \\ ${ }^{1}$ Civil and Environmental Engineering, University of Illinois Urbana-Champaign \\ Keywords: stop spacing, bus stop, transit, bus, public transportation \\ https://doi.org/10.32866/001c.27373
}

Findings

This article introduces a database of bus stop spacings for 43 cities in the United States derived from GTFS files published in late 2019. Weighting each spacing by the number of times a bus traverses it, we produce distributions and summary statistics. The overall mean spacing is 313 meters. Las Vegas' RTC has the widest mean spacing $(482 \mathrm{~m})$ and Philadelphia's SEPTA the narrowest $(214 \mathrm{~m})$. We also compare spacings within agencies' "core" cities to those outside.

\section{Questions}

Bus stop spacing refers to the distance that a bus travels from one stop to the next. Much theoretical analysis has focused on the choice of bus stop spacing (see extensive discussions in Daganzo and Ouyang 2019), which impacts how much time is spent braking and accelerating at stops as well as walking distances. Still, there is little hard data available as to what stop spacings actually are in the United States. One refrain in the literature is that US cities commonly have seven to ten bus stops per mile (Furth and Rahbee 2000; ElGeneidy et al. 2006). The source for this claim can be traced to Reilly (1997, 4 ), who says "It is common European practice to have stops spaced at 3 or 4 per mile in contrast with 7 to 10 stops per mile, which is common in the United States," though the study does not cite a particular source for this fact.

This study uses General Transit Feed Specification (GTFS) (Wong 2013) data published by 43 US transit agencies to build a dataset of stop spacings, available at Pandey and Lehe (2021a), in which each row represents one traversal of a spacing. By "traversal" we mean one instance of a bus traveling from one stop to the next stop on the trip. The GTFS files were all published in late 2019-before the service changes wrought by COVID-19. This article introduces the dataset, defines terms and answers some questions using the database:

1. What are the summary statistics?

2. How do the distributions of stop spacings look?

3. How do mean stop spacings differ inside and outside of the "core" cities served by an agency?

\section{Methods}

\subsection{Definitions}

We define stop spacing as the distance between two stops along the route of the bus. It includes the distance traveled along any bends in the road. 

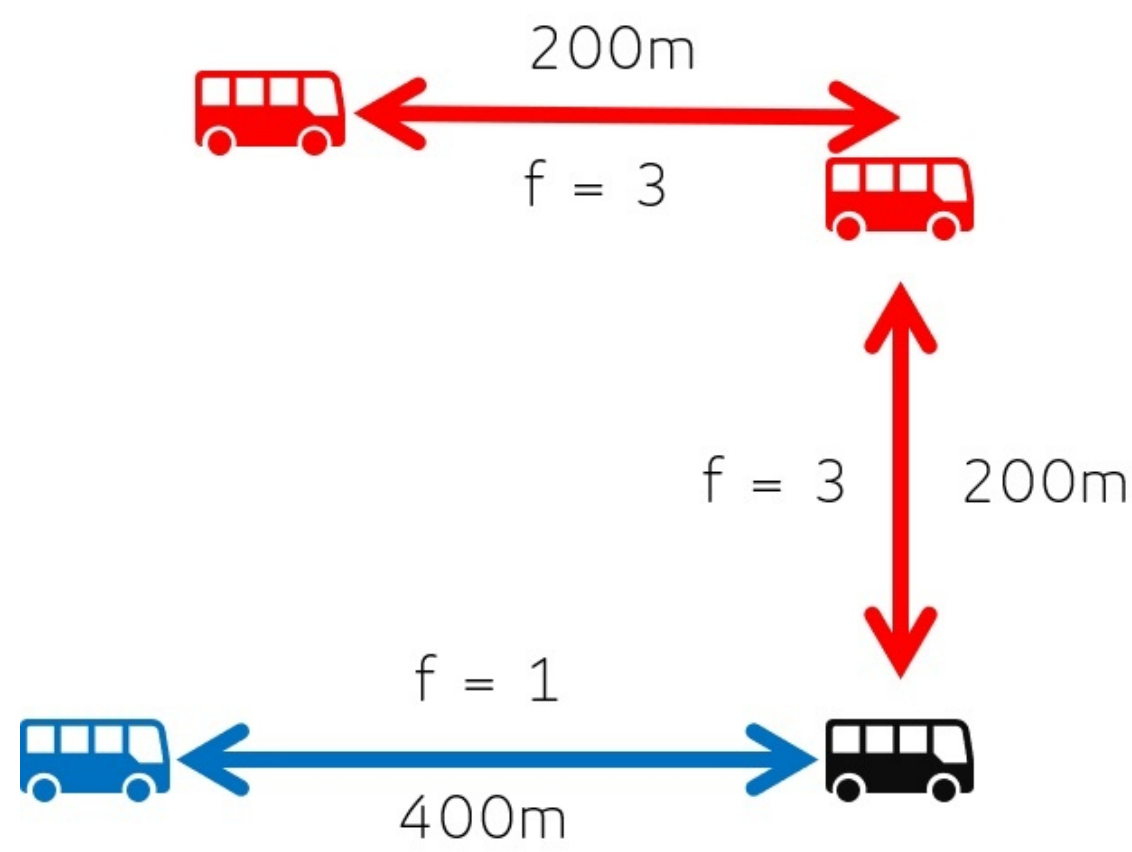

Figure 1. Example Transit Network

For distributions and summary statistics of stop spacings, we apply what we call traversal weighting: that is, if the schedule has buses move directly from stop A to stop B 100 times before the schedule repeats, then that spacing is counted 100 times.

To illustrate, consider the simple bus system shown in Figure 1, which shows a network with two routes and three stops. The blue route has two stops spaced $400 \mathrm{~m}$ apart and a frequency of 1 . The red route has three stops, spaced $200 \mathrm{~m}$ apart, and a frequency of 3 . The traversal-weighted mean stop spacing for the network in Figure 1 is

$$
\frac{400+200 \cdot 3+200 \cdot 3}{1+3 \cdot 2}=228.57 \quad(m) .
$$

If an omnipresent driver were to drive every bus, this is the mean distance he or she would travel between stops on this network.

\subsection{Calculation}

Pereira, Andrade, and Bazzo (2020) introduces an R-package, $g t f s 2 g p s$, which converts GTFS files to a database in which each row describes the location of a vehicle on a scheduled trip at a point along its route-including at all stops. One piece of data in each row is the cumulative distance that the vehicle has traveled since the start of the current trip. We use this database to produce another database, akin to the one in Table 1 , in which each row represents 


\begin{tabular}{|c|c|c|}
\hline spacing & loc1 & loc2 \\
\hline$\vdots$ & $\vdots$ & $\vdots$ \\
$x_{i}$ & $\left(\operatorname{lat}_{1}, \operatorname{lng}_{1}\right)_{i}$ & $\left(\operatorname{lat}_{2}, \operatorname{lng}_{2}\right)_{i}$ \\
$x_{i+1}$ & $\left(\operatorname{lat}_{1}, \operatorname{lng}_{1}\right)_{i+1}$ & $\left(\operatorname{lat}_{2}, \operatorname{lng}_{2}\right)_{i+1}$ \\
$\vdots$ & $\vdots$ & $\vdots$ \\
\hline
\end{tabular}

one traversal, giving the distance traveled between the traversal's two stops and their locations. Example code doing so for Ann Arbor is at Pandey and Lehe (2021b).

The general procedure is as follows: First, starting with the initial database produced by $g t f s 2 g p s$, we filter out all non-bus trips and all rows that do not correspond to a location at a stop, so that the database only contains information about buses when they are at stops. Next, for each stop along each trip, we subtract the cumulative distance traveled (from the start of the trip) when the bus is at the preceding stop from the cumulative distance traveled at the given stop, which gives the distance traveled between the stops. This difference is stored as a row in the new database along with both stops' coordinates, and the database is made available at Pandey and Lehe (2021a).

\section{Findings}

We apply the method described in Sec. 2.2 to 43 US cities. The sample includes the six most populated US cities as well as many smaller cities chosen to capture a diversity of city types and regions. The only systematic requirement for inclusion was that a city's GTFS files be sufficiently "filled in" for $g t f s g p s$ to convert the GTFS files to a GPS database. To run gtfs2gps requires that a GTFS bundle includes certain files: the optional 'shapes.txt' file and either the optional 'frequency.txt' or certain optional columns in the required 'stop_times.txt' file, so it cannot run when agencies do not include some optional data. The particular agency corresponding to each city ${ }^{1}$ is listed in Table 2. 
Table 2. Summary Statistics (traversal-weighted) for stop spacing (in [m]) in US cities

\begin{tabular}{|c|c|c|c|c|c|c|c|c|}
\hline City & Agency & Mean & Std. Deviation & Q25 & Median & Q75 & Core Mean & ExCore Mean \\
\hline Ann Arbor & Ann Arbor Area Transportation Authority & 383 & 213 & 245 & 325 & 443 & 353 & 438 \\
\hline Boston & Cape Cod Regional Transit Authority & 283 & 206 & 174 & 234 & 323 & 288 & 280 \\
\hline Buffalo & Niagara Frontier Transportation Authority & 262 & 199 & 170 & 218 & 289 & 224 & 328 \\
\hline Charlotte & Charlotte Area Transit System & 393 & 282 & 228 & 320 & 455 & 382 & 530 \\
\hline Cincinnati & Southwest Ohio Regional Transit Authority & 279 & 210 & 167 & 237 & 320 & 265 & 329 \\
\hline Cleveland & Greater Cleveland Regional Transit Authority & 275 & 185 & 188 & 243 & 317 & 263 & 289 \\
\hline Columbus & Central Ohio Transit Authority & 369 & 229 & 240 & 317 & 420 & 357 & 423 \\
\hline Dallas & Dallas Area Rapid Transit & 300 & 250 & 176 & 242 & 342 & 283 & 372 \\
\hline Denver & Regional Transportation District,America/Denver & 408 & 275 & 261 & 353 & 451 & 373 & 433 \\
\hline Des Moines & Des Moines Area Regional Transit Authority & 273 & 188 & 177 & 227 & 305 & 247 & 445 \\
\hline Detroit & Detroit Department of Transportation & 258 & 159 & 182 & 222 & 292 & 245 & 363 \\
\hline Fresno & Fresno Public Transportation (FAX) & 392 & 220 & 264 & 358 & 450 & 389 & 413 \\
\hline Gainesville & Regional Transit System & 263 & 122 & 185 & 231 & 295 & 263 & NA \\
\hline Houston & Metropolitan Transit Authority of Harris County & 306 & 187 & 198 & 256 & 357 & 300 & 378 \\
\hline Indianapolis & Indianapolis Public Transportation Corporation & 333 & 233 & 196 & 264 & 389 & 331 & 356 \\
\hline Jacksonville & Jacksonville Transportation Authority & 450 & 387 & 245 & 341 & 497 & 448 & 520 \\
\hline Kansas City & Kansas City Area Transportation Authority & 355 & 278 & 199 & 273 & 411 & 329 & 437 \\
\hline Los Angeles & Los Angeles County Metropolitan Transportation Authority & 402 & 294 & 243 & 341 & 434 & 392 & 418 \\
\hline Las Vegas & Regional Transportation Commission of Southern Nevada & 482 & 225 & 362 & 425 & 529 & 462 & 491 \\
\hline Memphis & Memphis Area Transit Authority & 280 & 246 & 147 & 214 & 328 & 278 & 408 \\
\hline Miami & Miami-Dade Transit & 349 & 297 & 192 & 260 & 388 & 288 & 372 \\
\hline Milwaukee & Milwaukee County Transit System & 278 & 175 & 185 & 232 & 354 & 269 & 299 \\
\hline Minneapolis & Metro Transit & 279 & 212 & 192 & 209 & 300 & 261 & 292 \\
\hline New York & Metropolitan Transportation Authority Bus Company & 328 & 283 & 178 & 240 & 353 & 327 & 448 \\
\hline Oakland & AC Transit & 344 & 236 & 207 & 283 & 400 & 306 & 371 \\
\hline Philadelphia & Southeastern Pennsylvania Transportation Authority & 214 & 179 & 137 & 172 & 227 & 186 & 318 \\
\hline Phoenix & Valley Metro & 446 & 241 & 332 & 402 & 477 & 425 & 469 \\
\hline Pittsburgh & Port Authority of Allegheny County & 268 & 276 & 143 & 190 & 277 & 235 & 319 \\
\hline Portland & TRIMET & 314 & 196 & 204 & 268 & 361 & 292 & 357 \\
\hline Providence & Rhode Island Public Transit Authority & 336 & 250 & 201 & 275 & 380 & 296 & 358 \\
\hline Salt Lake City & Utah Transit Authority & 374 & 285 & 215 & 291 & 428 & 328 & 392 \\
\hline
\end{tabular}




\begin{tabular}{|c|c|c|c|c|c|c|c|c|}
\hline City & Agency & Mean & Std. Deviation & Q25 & Median & Q75 & Core Mean & ExCore Mean \\
\hline San Antonio & VIA Metropolitan Transit & 338 & 272 & 201 & 257 & 373 & 327 & 481 \\
\hline Seattle & $\mathrm{ST}, \mathrm{KCM}, \mathrm{CT}, \mathrm{KT}, \mathrm{PT}, \mathrm{AT}, \mathrm{DCB}$ & 403 & 261 & 250 & 350 & 455 & 359 & 467 \\
\hline San Francisco & San Francisco Municipal Transportation Agency & 248 & 174 & 165 & 210 & 286 & 245 & 509 \\
\hline St. Louis & Metro St. Louis & 316 & 234 & 184 & 262 & 372 & 289 & 334 \\
\hline Tampa & Hillsborough Area Regional Transit & 392 & 282 & 220 & 324 & 457 & 347 & 468 \\
\hline Tucson & SunTran & 443 & 252 & 326 & 399 & 473 & 427 & 558 \\
\hline Tulsa & Metropolitan Tulsa Transit Authority & 382 & 364 & 192 & 271 & 438 & 375 & 766 \\
\hline
\end{tabular}




\begin{tabular}{|c|c|}
\hline stops/mile & stop spacing (meters) \\
\hline 10 & 161 \\
7 & 230 \\
4 & 402 \\
3 & 536 \\
\hline
\end{tabular}

The database can be put to several uses. One is to compare summary statistics. (To aid comparison, Table 3 translates into meters the 3, 7, 4 and 10 stops per mile mentioned in Reilly 1997.) Summary statistics appear in Table 2, where Q25 and Q75 refer to the $25^{\text {th }}$ and $75^{\text {th }}$ percentile, respectively. The Southeastern Pennsylvania Transportation Authority in Philadelphia has the narrowest mean stop spacing of $223 \mathrm{~m}$, while Las Vegas' Regional Transportation Commission of Southern Nevada the widest at $446 \mathrm{~m}$. The mean spacing across the whole dataset is $313 \mathrm{~m}$, which amounts to slightly more than 5 stops per mile.

Alternatively, we can also visualize distributions of spacings. Figure 2 shows histograms of the stop spacing distributions for Cincinnati, Boston, and Los Angeles. Note that Boston's spacings are distributed more tightly than those of Los Angeles.

The database can also be combined with geographic data, since we include the locations of both stops in each spacing. As a simple illustration, we use city boundary shapefiles downloaded from Centers for Disease Control and Prevention (2020) to calculate the mean spacing inside and outside each agency's "core" city, which we define to be the most populated city that the agency serves. If both stops involved in a traversal fall within the core city, we classify the traversal as being inside the core. The last two columns of Table $\underline{2}$ list the resulting means, and Figure 3 visualizes them. Note several facts. First, spacings are generally larger than 7 per mile, and in some cities within the band of 3 to 4 stops per mile claimed to be typical of European cities. Second, stop spacings are larger outside than inside core cities. Third, cities mostly established before the automobile era (e.g., Cleveland) have relatively smaller spacings.

This exercise also demonstrates why it is critical for comparisons to be clear about sourcing. For instance, Chicago's suburban communities are mainly served by PACE Suburban Bus, but our dataset for Chicago comes from the Chicago-focused CTA; hence, the spacing inside and outside the core are similar.

The authors hope the dataset and code provided can serve many purposes. US agencies have tried to consolidate bus stops-e.g., Pittsburgh most recently (Blazina 2020) - and decision-makers might benefit from knowing how their 

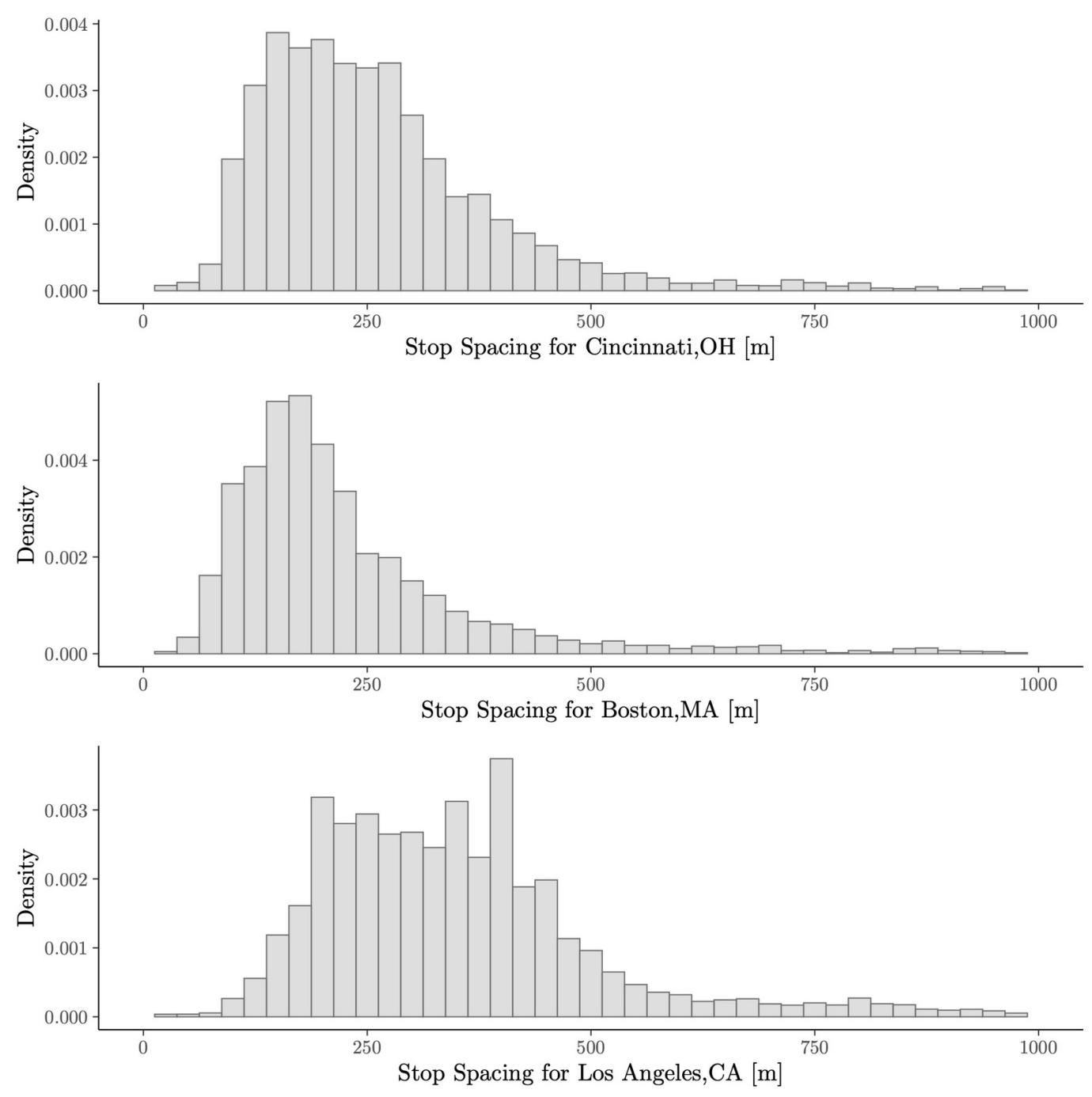

Figure 2. Traversal-weighted stop spacing distributions

cities' spacings compare. Similar data could also be collected for cities in other countries. Spacings may also be classified by census tract to answer questions such as: does stop spacing decline with population and/or job density? It may also be worthwhile for researchers to write code targeted more efficiently at studying stop spacings than $g t f s 2 g p s$ is.

Submitted: July 09, 2021 AEST, Accepted: August 12, 2021 AEST 


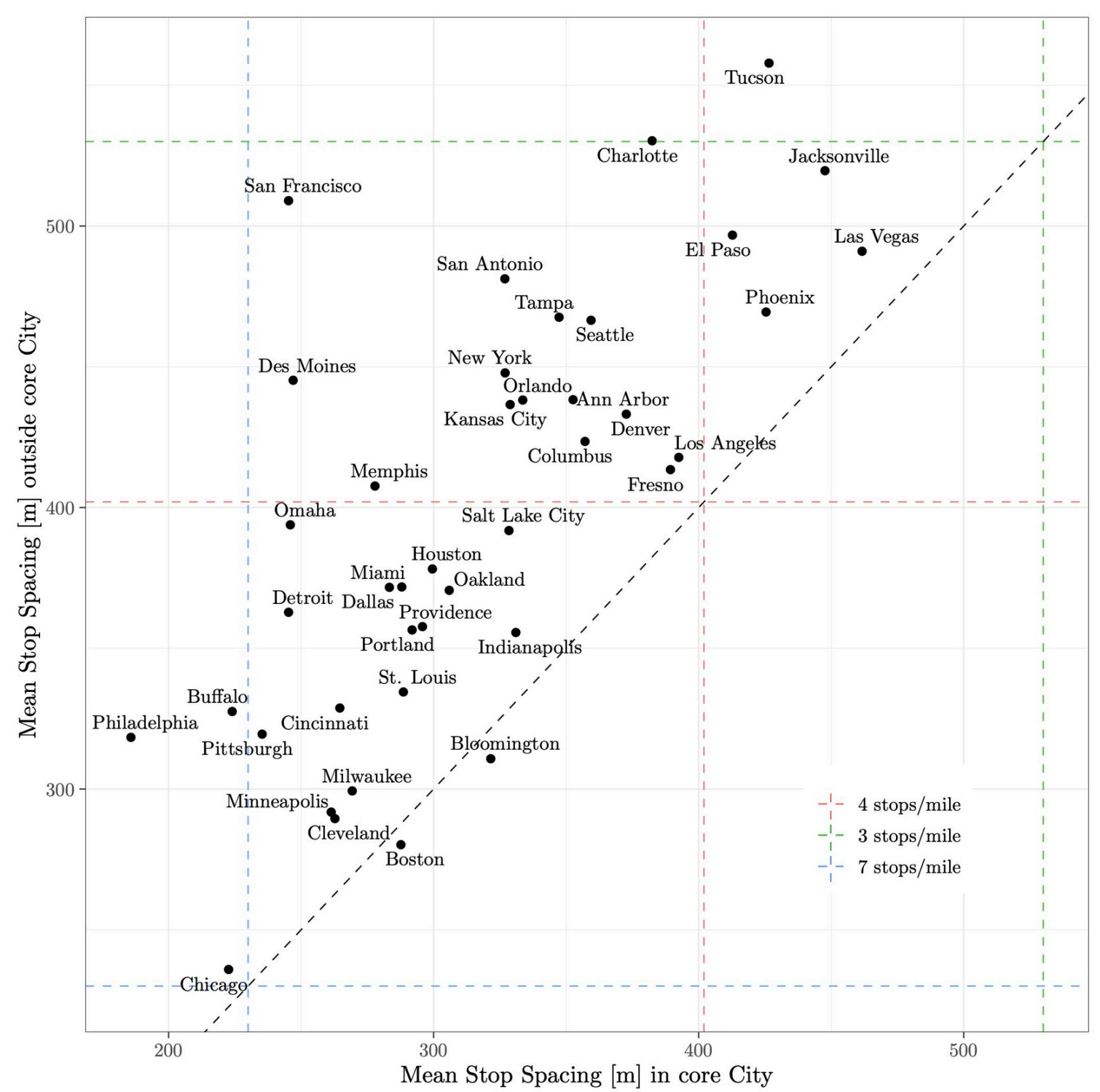

Figure 3. Average Stop Spacing inside and outside core city

This is an open-access article distributed under the terms of the Creative Commons Attribution 4.0 International License (CCBY-SA-4.0). View this license's legal deed at https://creativecommons.org/ licenses/by-sa/4.0 and legal code at https://creativecommons.org/licenses/by-sa/4.0/legalcode for more information. 


\section{REFERENCES}

Blazina, Ed. 2020. "Port Authority's Initial Bus Stop Eliminations Showing on-Time Improvements." Pittsburgh Post-Gazette, February 23, 2020. https://www.post-gazette.com/news/transportation/ 2020/02/23/Port-Authority-bus-stops-on-time-performance-improvements-efficiency-transit/ stories/202002230032.

Centers for Disease Control and Prevention. 2020. "500 Cities: City Boundaries.” https://chronicdata.cdc.gov/500-Cities-Places/500-Cities-City-Boundaries/n44h-hy2j/.

Daganzo, Carlos F, and Yanfeng Ouyang. 2019. Public Transportation Systems. WORLD SCIENTIFIC. https://doi.org/10.1142/10553.

El-Geneidy, Ahmed M., James G. Strathman, Thomas J. Kimpel, and David T. Crout. 2006. "Effects of Bus Stop Consolidation on Passenger Activity and Transit Operations." Transportation Research Record, no. 1971: 32-41. https://doi.org/10.3141/1971-06.

Furth, Peter G, and Adam B Rahbee. 2000. "Dynamic Programming and Geographic Modeling.” Transportation Research Record: Journal of the Transportation 00-0870 (00): 15-22.

Pandey, Ayush, and Lewis Lehe. 2021a. "Replication Data for: Distributions of Bus Stop Spacings in the United States.” Harvard Dataverse. https://doi.org/10.7910/DVN/AKDQJQ.

- - . 2021b. Stop Spacing Database Code. GitHub.

Pereira, Rafael H. M., Pedro R. Andrade, and Joao Bazzo. 2020. Gtfs2gps: Converting Transport Data from GTFS Format to GPS-Like Records. R Package Version 1.0-5. Vienna: R Found. Stat. Comput. https://CRAN.R-project.org/package=gtfs2gps.

Reilly, Jack M. 1997. "Transit Service Design and Operation Practices in Western European Countries." Transportation Research Record:Journal of the Transportation Research Board 1604 (1): 3-8. https://doi.org/10.3141/1604-01.

Wong, James. 2013. "Leveraging the General Transit Feed Specification for Efficient Transit Analysis.” Transportation Research Record, no. 2338 (January): 11-19. https://doi.org/10.3141/2338-02. 